\title{
Prescription audit in a paediatric sickle cell clinic in South-West Nigeria: A cross-sectional retrospective study
}

Fadare Joseph Olusesan ${ }^{1}$, Olatunya Oladele Simeon ${ }^{2,3}$, Ogundare Ezra Olatunde $^{2,3}$, Oluwayemi Isaac Oludare ${ }^{2,3}$, Agaja Oyinkansola Tolulope ${ }^{3}$

1. Department of Pharmacology and Therapeutics, Ekiti State University, Ado-Ekiti, Nigeria

2. Department of Paediatrics, Ekiti State University, Ado-Ekiti, Nigeria

3. Department of Paediatrics, Ekiti State University Teaching Hospital, Ado-Ekiti, Nigeria

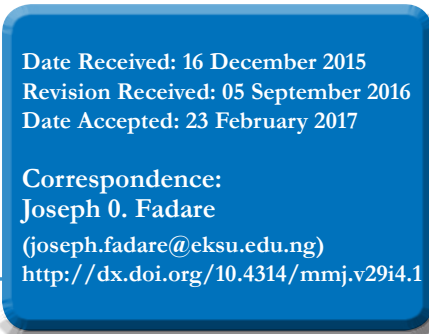

Background

Abstract

Sickle cell disease (SCD) is a genetic haematological disorder that affects millions of people around the world especially people of African heritage. The treatment of the symptoms of SCD includes the use of analgesics, antibiotics, and anti-malarial drugs. Studying the pattern of drug prescription is a veritable tool for establishing the current practice and how it conforms to existing guidelines.

Objectives

The main objective of this study was to assess the pattern of drug prescription in children with sickle cell disease (SCD) attending the paediatric outpatients' clinic of a tertiary care centre in Ado-Ekiti, South-West Nigeria.

Methods

This was a cross-sectional retrospective study carried out using the medical records of all patients with SCD who attended the paediatric outpatient clinic of the teaching hospital between January 1 and December 31, 2014. The information retrieved from the case notes included the bio-demographic data, associated co-morbid conditions and the list of prescribed drugs.

Results

A total of 202 SCD patients aged below 18 years were seen in the clinic during the study period with males accounting for $61.9 \%$ of them. The mean age of all patients was $6.9 \pm 3.8 \mathrm{yrs}$. A total of 1015 medications were prescribed during the study period giving a mean of $5.02 \pm 1.9$. Vitamins/micronutrients, anti-malarial drugs, antibiotics and analgesics accounted for $41.4 \%, 29.0 \%, 15.7 \%$ and $13.9 \%$ of all prescribed drugs respectively. Antibiotics from the penicillin group were the most commonly prescribed followed by macrolides and cephalosporins while Ibuprofen (60.3\%) and Acetaminophen $(32.6 \%)$ were the commonly prescribed analgesics. Conclusion

High rate of antibiotic prescription, low use of opioid analgesics and non- prescription of prophylactic penicillin/ pneumococcal vaccination were the main findings in this study. There is need for the introduction of standard treatment protocols for this group of patients.

\section{Introduction}

Sickle cell disease (SCD) is a genetic haematological disorder with its clinical manifestation starting usually in early childhood and sometimes during infancy. There are different forms of SCD but individual homozygous for the $\mathrm{HbS}$ gene has the most severe form called sickle cell anemia $(\mathrm{SCA})^{1,2}$. It affects millions of people around the world but the greatest burden of SCD is in sub-Saharan Africa (SSA), where approximately $75 \%$ of the global 300,000 births of affected children occur ${ }^{1,2}$. Understandably, because of its large population, Nigeria has the largest burden of SCD in Africa with a prevalence of 20-30 per 1000 live births and SCA is the variant of SCD commonly encountered ${ }^{3}$. The Nigerian government responded to the huge disease burden recently by launching a national guideline for the care of person with SCD in November 2014 $4^{4}$. The disease condition is characterized by chronic hemolytic anaemia, severe painful episodes due to vaso-occlusion and multi-organ ischaemic damage which inadvertently affects the quality of life of these patients ${ }^{5}$. Also, patients with SCD are more prone to bacterial infections and severe forms of malaria due to reduced splenic activity. The World Health Organization (WHO) has identified that most of the mortalities caused by SCD and its complications can be prevented through simple and cost-effective comprehensive care ${ }^{6}$. These include the immediate treatment of acute events and prophylaxis against infections through vaccinations and other medications. The treatment of the symptoms of SCD includes adequate hydration, blood transfusion, use of analgesics, antibiotics, and anti-malarial drugs.

Despite the established fact that pain secondary to vasoocclusive crisis is the most common symptom of SCD and responsible for presentation at the emergency department, studies conducted worldwide have shown a gross undertreatment of pain ${ }^{7,8}$. Also, the use of prophylactic medications and vaccinations has been shown to be effective in preventing infections in patients with $\mathrm{SCD}^{9,10}$. These aspects of care and others are well outlined in the newly launched guidelines for the care of persons with SCD in Nigeria. For example, the guideline stipulates that children with SCD should have prophylaxis for malaria and bacterial infections with proguanil and penicillin $\mathrm{V}$ respectively. In addition, they are required to recieve some additional vaccines among other cares ${ }^{4}$.

A prescription audit represents a veritable tool for establishing the pattern of disease treatment generally among patients ${ }^{11}$. In addition to establishing pattern of drug use, audit of prescriptions is essential to identify various categories of non-rational drug prescribing such as polypharmacy and irrational use of antibiotics ${ }^{12}$. Prescription audits also describe trends in management of diseases and adherence to established international or national treatment 
guidelines ${ }^{13}$. Non-rational prescription of antibiotics is associated with antimicrobial resistance, treatment failures and increased healthcare costs ${ }^{14}$. In patients with SCD, a prescription audit would give information about types of analgesics, antibiotics and anti-malarial drugs prescribed for patients. Some prescription audits have previously been conducted among children attending the children outpatient clinics of secondary and tertiary healthcare centres in Nigeria, ${ }^{15-17}$ but to the knowledge of the authors this is the first study on drug prescribing pattern among paediatric SCD patients. The main objective of this study was to assess the pattern of drug prescription in children with SCD attending a paediatric outpatients' clinic of a tertiary care centre in Ado-Ekiti, South-West Nigeria. Additional objectives included associated co-morbid conditions and detailed analysis of prescribed analgesics, antibiotics and anti-malarial medications.

\section{Methods}

\section{Study Setting}

The study was conducted in the paediatric outpatient clinic of the Ekiti State University Teaching Hospital, Ado-Ekiti, South-West Nigeria. This tertiary level healthcare facility provides medical care for the population of Ado-Ekiti, the capital city, and other communities in Ekiti State, South-West Nigeria. The paediatric department is well staffed with its components of medical officers, registrars, consultants and nursing staff and runs a weekly haematology clinic where patients with SCD are seen. The department also runs an emergency unit where patients that require observation and admission are attended to. There were 238 registered patients at the paediatric SCD clinic at the time of this review out of which only 208 attend the clinic regularly. The regular attendees comprised $136(65.4 \%)$ males and 72 $(34.6 \%)$ females. All diagnoses of disease conditions were made based on clinical features and laboratory confirmation. For example, all cases of suspected malaria i.e. children presenting with fever (axillary temperature $\geq 37.5^{\circ} \mathrm{C}$ ) and no other clinical features referable to other illnesses apart from malaria, had parasitological tests to confirm the diagnosis of malaria through blood film examination by light microscopy and or rapid diagnostic test kits.

\section{Method}

A cross-sectional retrospective study was carried out using the medical records of all patients with SCD who attended the paediatric outpatients' clinic of the teaching hospital between January 1 and December 31, 2014. The data was extracted from the case notes during the months of January and February, 2015.

\section{Sampling procedure}

Using convenience sampling, medical records of all children and adolescents ( $<18$ years) with SCD who attended the SCD clinic during the one year period were selected for the study. Records of patients who were admitted to the emergency room or the wards because of the severe nature of their presentation were excluded from the study.

\section{Data collection}

The information retrieved from the case notes included the bio-demographic data, associated co-morbid conditions and the list of prescribed drugs. Also, the dosages and routes of administration of the medications were recorded. A data collection instrument was developed by the researchers based on the items listed above and pre-tested using medical records of ten patients to identify potential problems. Two medical officers were trained by the principal investigator on how to record the required information and the completed data forms were reviewed by two of the co-investigators to ensure that all vital information was correctly captured. The following drug use indicators were assessed using the WHO guidelines on investigation of drug use in health care facilities: average number of drugs per prescription, percentage of encounters with antibiotics, percentage of encounters with analgesics, percentage of drugs prescribed by generic name and percentage of encounters with injections ${ }^{18}$. The percentage of encounters with anti-malarial drugs was also included as the study was conducted among children and adolescents residing in a malaria endemic area.

\section{Statistical Analysis}

Data were analyzed using Statistical Package for Social Sciences (SPSS) version 17 software (IBM Corporation, Armonk, NY, USA). Results were expressed as means, frequencies and percentages. Chi square was used to determine the level of significance of groups of categorical variables with $\mathrm{P}$ values $<0.05$ considered significant. Association between age groups, number of drugs per prescription, number of analgesic drugs and number of antimicrobials was explored by univariate analysis.

\section{Ethical Considerations}

Ethical approval was obtained from the Hospital Research Ethics Committee before the commencement of the study.

\section{Results}

The medical records of 202 SCD patients were used for the study. Males accounted for $61.9 \%$ while children less than 5 years formed the largest group $(87 ; 43.1 \%)$ followed by those between $5-10$ years $(81 ; 40.1 \%)$ and those above 10 years $(34 ; 16.8 \%)$. The mean age of all patients was $6.9 \pm 3.8$ yrs. Malaria $(80 ; 39.6 \%)$ and respiratory tract infection (32; $15.8 \%$ ) were the most common co-morbid conditions while vaso-occlusive crisis $(40 ; 19.8 \%)$ was the most diagnosed sickling syndrome. Table 1 shows some of the demographic details and established diagnoses (please note that patients may have one or more co-morbidities).

A total of 1015 medications were prescribed during the study period giving a mean of $5.02 \pm 1.9$. Figure 1 shows the frequency distribution of prescribed medications. Seventy-eight patients $(38.6 \%)$ had four medications or less prescribed while $124(61.4 \%)$ had more than four medications. Vitamins/micronutrients, anti-malarial drugs, antibiotics and analgesics accounted for $41.4 \%, 29.0 \%$, $15.7 \%$ and $13.9 \%$ of all prescribed drugs respectively. One hundred and ninety patients $(94.1 \%)$ had at least one antimalarial drug prescribed while $183(90.6 \%), 139(68.8 \%)$ and $124(61.4 \%)$ had an encounter with vitamins, antibiotics and analgesics respectively. Thirty-six patients $(17.8 \%)$ had drugs administered in injectable form.

A total of 159 antibiotics were prescribed with drugs from the penicillin group most commonly prescribed followed by macrolides and cephalosporins (Figure 3). Erythromycin (38; 23.8\%), Amoxycillin/Clavulanic acid (30; 18.8\%), Cefuroxime (26;16.3\%), Amoxycillin (18; 11.3\%) and Ciprofloxacin $(12 ; 7.5 \%)$ were the most common prescribed antibiotics. Paludrine, the prophylactic anti-malarial, was prescribed for $(92 ; 48.4 \%)$ patients while the artemisinin- 
based combination of Artesunate-Amodiaquine (40;21.1\%) and Artemether-Lumefantrine $(37 ; 19.5 \%)$ were prescribed for the treatment of acute malaria. Ibuprofen $(85 ; 60.3 \%)$, Acetaminophen (46; 32.6\%) and Diclofenac (9; 6.4\%) were the commonly prescribed analgesics. Pentazocine was prescribed only for one patient among the study participants. A comparison of the mean total number of prescribed drugs and antibiotics among the three age groups was not statistically significant $(\mathrm{P}=.308$ and .650 respectively). There was however a statistically significant difference in the mean number of prescribed analgesics between the three age groups $(\mathrm{P}=.004)$.

\section{Discussion}

This study has described the morbidity pattern and the drugs prescribed in the treatment of children with Sickle cell disease in a centre in South-west Nigeria. Children aged less than five years formed the bulk of study participants; this is not too surprising as the diagnosis of SCD is made usually during this period and caregivers are faced with the challenges of how to manage this condition. Also, during these early years, the immunity of the children is not well developed to be able to withstand the assault of the myriads of infections they are susceptible to. In fact, mortality in children with SCD has been documented to be highest among the under-five age group $^{19,20}$.

Malaria and respiratory tract infections were the most common medical conditions in children with SCD presenting at the healthcare facility. This is not surprising as the study area is located within the holo-endemic malaria transmission region. It is also an established fact that infections and malaria are among the most common triggers of different types of crisis necessitating admissions in children with $\mathrm{SCD}^{21}$, 22Vaso-occlusive crisis was the most frequently diagnosed clinical phenotype among patients in this study, similar to results from work carried out by Ibidapo et al and Olabode et al in Lagos and Ibadan, Nigeria respectively ${ }^{23,24}$. This finding buttresses the earlier mentioned role of malaria and infections as triggers of crisis in $\mathrm{SCD}^{21,22}$.

The mean number of prescribed drugs found in this study was $5.0 \pm 1.9$, similar to 4.5 reported by Jimoh et al in a study conducted among patients with SCD in North-west Nigeria $^{25}$. For the under-fives in this study, the mean of prescribed drugs was 4.9 much higher than 2.6 and 3.1 reported in other Nigerian studies conducted among children younger than five years of age ${ }^{17,26}$. Similar findings have also been reported in studies conducted among children in India, Oman and Italy with a mean number of prescribed drugs $2.3,2.3$ and 3.1 respectively ${ }^{27-29}$. The higher mean reported in studies conducted among patients with SCD is likely due to differences in patient population, associated co-morbidities and routine medications prescribed for them. These routine medications are however very necessary because patients with SCD are more prone to certain infections due to their poorer immunity status ${ }^{30}$.

A total of 159 antibiotics were prescribed for patients in this study, representing $15.7 \%$ of all prescribed medications in this study with $68.8 \%$ of patients having at least one antibiotic prescribed. This result is higher than $8.7 \%$ reported in the earlier cited study among SCD patients in Nigeria ${ }^{25}$. This difference may be due to the fact that the latter study included both paediatric and adult patients with SCD with different profiles of clinical sickling syndromes and co- morbidities. Antibiotic prescribing reported in some studies among non-SCD patients range between $28 \%$ and $33.3 \%$ and this is much higher than what is found in this study. ${ }^{17,31,32}$ This may also be due to the approach of clinicians towards management of febrile illness in children with unjustified prescription of antibiotics. Non-rational prescription and use of antibiotics is associated with increased antimicrobial resistance, worsening morbidity and increased healthcare costs especially in resource-limited settings ${ }^{33-35}$. Prophylactic penicillin has been found to be effective in the prevention of pneumococcal infections among SCD patients especially in children less than five years old ${ }^{9,36}$. In this study, no patient had penicillin prophylaxis, a practice not in keeping with internationally accepted guidelines ${ }^{37}$. In a recent Nigerian study conducted across 18 sickle cell clinics, only eight of them routinely gave prophylactic penicillin ${ }^{38}$. This is in contrast to a study conducted in Brazil where $76.1 \%$ of the patient population received penicillin prophylaxis ${ }^{39}$.

The prophylactic anti-malarial Proguanil (Paludrine ${ }^{\circledR}$ ) was prescribed for $92(48.4 \%)$ patients; this is much less than $73.4 \%$ reported among SCD patients in North-west Nigeria ${ }^{25}$. The need for prompt and effective treatment of malaria and infections in patients presenting in the clinic may explain this relatively low level of Proguanil prescription during the acute phase of illness. The artemisinin-based combinations (Artesunate-Amodiaquine and Artemeter-Lumefantrine) were the most commonly used antimalarial drugs in keeping with findings from other Nigerian studies ${ }^{17,40}$.

Vaso-occlusive crisis manifesting as bone pains is a major cause of emergency room visits and hospitalizations hence pain relief is a core aspect of treating patients with SCD. Analgesics constituted $13.9 \%$ of all prescribed drugs with 124 (61.4\%) having at least one analgesic drug; a finding that is lower than $30.1 \%$ recorded in the earlier cited study among sickle cell patients in North-west Nigeria $a^{25}$. Ibuprofen and Acetaminophen were the most prescribed analgesics in this study while only one patient had Pentazocine (an opioid) prescribed. This might be due to the perceived degree of the pain severity by the attending physicians, given the belief that most patients with severe pains will be taken directly to the children emergency ward in the hospital. Also, studies have shown a tendency towards under-prescribing of opioid analgesics by medical practitioners because of perceived fear of both physical and psychological dependence ${ }^{41,42}$. For these reasons, the attending physicians may have avoided prescribing opioid analgesics for outpatients even though there is no regulation against the practice. This finding is in keeping with the results of a systematic review of paediatric analgesic use in Africa which reported that only $0.2 \%$ of children had opioid analgesic prescribed ${ }^{43}$. This is in contrast to current guidelines that recommend rapid initiation of opioids in the management of vaso-occlusive crises $^{37}$. Inadequate treatment of pain among patients with SCD is one of the shortfalls of the management of SCD and it has been attributed to the wrong perception of caregivers and physicians about psychological dependence or addiction following opioid use ${ }^{8,44}$. Also, the subjectivity of the reported pain and the coping ability of patients may affect the way pain is observed by patients' relatives and medical staff ${ }^{7,45}$. Strategies that have been used to address the poor management of pain among patients with SCD include the use of various pain assessment scales and addressing the psychosocial component of the experience ${ }^{46-48}$. Findings from other studies linked inadequate analgesia in patients 
with SCD with worsening morbidity and adverse effects on the overall quality of life hence, the need for interventions to improve on this practice ${ }^{5,8}$.

The use of hydroxyurea has contributed significantly to the reduction in morbidity and mortality and improvement of quality of life of patients with $\mathrm{SCD}^{37,49}$. None of the patients was on hydroxyurea during the duration of this study and this may be due to poor knowledge and perception of physicians towards its use and the issue of cost and its side effects. A recent comparative study among sickle cell patients from Nigeria and the USA showed significant lower use of hydroxyurea among the Nigerian cohort ${ }^{50}$. Also the locally developed anti-sickling agent, Ciklavit ${ }^{\circledR}$, which has been found to be effective in reducing sickling episodes, was not prescribed for any of the patients during the study ${ }^{51}$. This brings to fore the need for government to either subsidize these medications to ensure their affordability or speed up its coverage under the National Health Insurance Scheme.

\section{Study Limitations}

This study was conducted in only one centre and this fact may affect the generalization of its results. We are also aware of the possibility of patients using drugs not prescribed by doctors especially as the regulatory environment for medicines in Nigeria is poor; hence the possibility of underreporting of drug use among this population. Though majority of the patients were booked for routine clinic appointment, some might have presented acutely with resultant effects on the drug prescription pattern. It was also noted that very few prescription audits among patients with SCD had been conducted in Nigeria and indeed the sub-Saharan region hence the inability of finding similar studies for comparison of results. This might impact on the interpretation of our results in the context of the general population. Finally, the retrospective nature of the study may be associated with missing data and other vital information that may be relevant. This was observed in this study as records of six patients could not be traced for analysis.

\section{Conclusion}

High rate of antibiotic prescription, low use of opioid analgesics and non- prescription of prophylactic penicillin/ pneumococcal vaccination were the main findings in this study. There is a need to update medical practitioners on the comprehensive approach to the management of SCD through introduction of treatment protocols. Inadequate analgesia in patients with SCD, apart from worsening morbidity, will also affect the overall quality of life. The observed gapsin the care of patients with SCD raise the need for health care providers to adhere to established guidelines and protocols while managing their patients. In view of the above, all efforts should be made to improve on every aspect of care and management of SCD patients by domesticating available guidelines.

\section{Source of Funding}

Nil

\section{Conflict of Interest}

Nil

\section{Acknowledgement}

The authors are grateful to the staff of the health information management department for their assistance in retrieving the medical records.

\section{References}

1.Adewoyin AS. Management of sickle cell disease: a review for physician education in Nigeria (sub-saharan Africa). Anemia 2015; 2015: 791498.

2.Rees DC, Williams TN, Gladwin MT. Sickle-cell disease. Lancet 2010; 376(9757): 2018-31

3.Anaemia WS-c. Report by the Secretariat. Fifty-ninth World Health Assembly 2006; 2

4.The National Guideline For The Control and Management of Sickle Cell Disease. 2014.

5.Bhagat VM, Baviskar SR, Mudey AB, Goyal RC. Poor health related quality of life among patients of sickle cell disease. Indian J Palliat Care 2014; 20(2): 107-11.

6.Makani J, Ofori-Acquah SF, Nnodu O, Wonkam A, Ohene-Frempong K. Sickle cell disease: new opportunities and challenges in Africa. Sci. World J;2013; 2013: 193252. doi.org/10.1155/2013/193252

7.Stinson J, Naser B. Pain management in children with sickle cell disease. Paediatr Drugs 2003; 5(4): 229-41.

8.Jacob E. Pain management in sickle cell disease. Pain Manag Nurs 2001; 2(4): 121-31.

9.Cober MP, Phelps SJ. Penicillin prophylaxis in children with sickle cell disease. J Pediatr Pharmacol Ther 2010; 15(3): 152-9.

10.Knight-Madden J, Serjeant GR. Invasive pneumococcal disease in homozygous sickle cell disease: Jamaican experience 1973-1997. J Pediatr 2001; 138(1): 65-70.

11.Wettermark B, Hammar N, MichaelFored C, et al. The new Swedish Prescribed Drug Register - Opportunities for pharmacoepidemiological research and experience from the first six months. Pharmacoepidemiol Drug Saf; 2007; 16(7): 726-35. doi: 10.1002/pds.1294.

12.Sisay M, Mengistu G, Molla B, Amare F, Gabriel T. Evaluation of rational drug use based on World Health Organization core drug use indicators in selected public hospitals of eastern Ethiopia: a cross sectional study. BMC Health Serv Res; 2017; 17(1): 161.doi: 10.1186/ s12913-017-2097-3.

13.van Kasteren ME, Kullberg BJ, de Boer AS, Mintjes-de Groot J, Gyssens IC. Adherence to local hospital guidelines for surgical antimicrobial prophylaxis: a multicentre audit in Dutch hospitals. J Antimicrob Chemother; 2003; 51(6): 1389-96. doi: 10.1093/jac/dkg264

14.Siddiqi S, Hamid S, Rafique G, et al. Prescription practices of public and private health care providers in Attock District of Pakistan. Int J Health Plann Manage 2002; 17(1): 23-40.

15.Tamuno I, Fadare JO. Drug prescription pattern in a Nigerian tertiary hospital. Trop J Pharm Res; 2012; 11(1):146-52. doi: 10.4314/tjpr. v11i1.19

16.Enwere OO, Falade CO, Salako BL. Drug prescribing pattern at the medical outpatient clinic of a tertiary hospital in southwestern Nigeria. Pharmacoepidemiol Drug Saf; 2007; 16(11): 1244-9. doi: 10.1002/ pds. 1475

17.Fadare J, Olatunya O, Oluwayemi O, Ogundare O. Drug prescribing pattern for under-fives in a paediatric clinic in South-Western Nigeria. Ethiop J Health Sci; 2015; 25(1): 73-8. doi: http://dx.doi.org/10.4314/ ejhs.v25i1.10

18.World Health Organization. How to investigate drug use in Health Facilities: selected drug use indicators. Geneva, 1993.

19.Jain D, Bagul AS, Shah M, Sarathi V. Morbidity pattern in hospitalized under five children with sickle cell disease. Indian J Med Res 2013; 138(3): 317-21.

20.McAuley CF, Webb C, Makani J, et al. High mortality from Plasmodium falciparum malaria in children living with sickle cell anemia on the coast of Kenya. Blood 2010; 116(10): 1663-8. 
21.Makani J, Komba AN, Cox SE, et al. Malaria in patients with sickle cell anemia: burden, risk factors, and outcome at the outpatient clinic and during hospitalization. Blood 2010; 115(2): 215-20.

22.Juwah AI, Nlemadim A, Kaine W. Clinical presentation of severe anemia in pediatric patients with sickle cell anemia seen in Enugu, Nigeria. Am J Hematol 2003; 72(3): 185-91.

23.Ibidapo MO, Akinyanju OO. Acute sickle cell syndromes in Nigerian adults. Clin Lab Haematol 2000; 22(3): 151-5.

24.Olabode JO, Shokunbi WA. Types of crises in sickle cell disease patients presenting at the haematology day care unit (HDCU), University College Hospital (UCH), Ibadan. West Afr J Med 2006; 25(4): 284-8.

25.Jimoh AO, Adebisi IM, Ndakotsu MA. Drug use pattern in sickle cell disease in a hematology unit of a teaching hospital in North-Western Nigeria; Ann Nigerian Med. 2014; 8(1): 32.doi: 10..4103/03313131.141027

26.Nwolisa CE, Erinaugha EU, Ofoleta SI. Prescribing practices of doctors attending to under fives in a children's outpatient clinic in Owerri, Nigeria. J Trop Pediatr 2006; 52(3): 197-200.

27.Al Balushi KA, Al-Sawafi F, Al-Ghafri F, Al-Zakwani I. Drug utilization pattern in an Omani pediatric population. J Basic Clin Pharm 2013; 4(3): 68-72.

28.Clavenna A, Bonati M. Drug prescriptions to outpatient children: a review of the literature. Eur J Clin Pharmacol 2009; 65(8): 749-55.

29.Dimri S, Tiwari P, Basu S, Parmar VR. Drug use pattern in children at a teaching hospital. Indian Pediatr 2009; 46(2): 165-7.

30.Tubman VN, Makani J. Turf wars: exploring splenomegaly in sickle cell disease in malaria-endemic regions. Br J Haematol; 2017; 177(6): 938-46. doi: 10.1111/bjh.14592

31.Thiruthopu NS, Mateti UV, Bairi R, Sivva D, Martha S. Drug utilization pattern in South Indian pediatric population: A prospective study. Perspect Clin Res 2014; 5(4): 178-83.

32.Elshout G, van Ierland Y, Bohnen AM, et al. Alarm signs and antibiotic prescription in febrile children in primary care: an observational cohort study. Br J Gen Pract 2013; 63(612): e437-44.

33.Ciorba V, Odone A, Veronesi L, Pasquarella C, Signorelli C. Antibiotic resistance as a major public health concern: epidemiology and economic impact. Annali di igiene : medicina preventiva e di comunita 2015; 27(3): 562-79.

34.Miyakis S, Pefanis A, Tsakris A. The challenges of antimicrobial drug resistance in Greece. Clin Infect Dis 2011; 53(2): 177-84.

35.Dik JW, Vemer P, Friedrich AW, et al. Financial evaluations of antibiotic stewardship programs-a systematic review. Front Microbiol 2015; 6: 317.

36.Gwaram HA, Gwaram BA. A systematic review of effectiveness of daily oral penicillin $\mathrm{v}$ prophylaxis in the prevention of pneumococcal infection in children with sickle cell anaemia. Niger J Med 2014; 23(2): 118-29.

37.Yawn BP, Buchanan GR, Afenyi-Annan AN, et al. Management of sickle cell disease: summary of the 2014 evidence-based report by expert panel members. JAMA 2014; 312(10): 1033-48.

38.Galadanci N, Wudil BJ, Balogun TM, et al. Current sickle cell disease management practices in Nigeria. Int Health 2014; 6(1): 23-8.

39.Fernandes TA, Medeiros TM, Alves JJ, et al. Socioeconomic and demographic characteristics of sickle cell disease patients from a lowincome region of northeastern Brazil. Rev Bras Hematol Hemoter 2015; 37(3): 172-7.

40.Ezenduka CC, Okonta MJ, Esimone CO. Adherence to treatment guidelines for uncomplicated malaria at two public health facilities in Nigeria; Implications for the 'test and treat' policy of malaria case management. J Pharm Policy Pract 2014; 7(1): 15.

41. Weinstein SM, Laux LF, Thornby JI, et al. Physicians' attitudes toward pain and the use of opioid analgesics: results of a survey from the Texas Cancer Pain Initiative. Southern medical journal 2000; 93(5): 479-87.

42.Bennett DS, Carr DB. Opiophobia as a barrier to the treatment of pain. J Pain Palliat Care Pharmacother; 2002; 16(1):105-9. https://doi. org/10.1080/J354v16n01_09

43.Madadi P, Enato EF, Fulga S, et al. Patterns of paediatric analgesic use in Africa: a systematic review. Arch Dis Child 2012; 97(12): 108691.

44.Labbe E, Herbert D, Haynes J. Physicians' attitude and practices in sickle cell disease pain management. J Palliat Care 2005; 21(4): 246-51.

45. Wright K, Adeosum O. Barriers to effective pain management in sickle cell disease. Br J Nurs 2009; 18(3): 158-61.

46.Myrvik MP, Brandow AM, Drendel AL, Yan K, Hoffmann RG, Panepinto JA. Clinically meaningful measurement of pain in children with sickle cell disease. Pediatr Blood Cancer 2013; 60(10): 1689-95.

47.Graumlich SE, Powers SW, Byars KC, Schwarber LA, Mitchell MJ, Kalinyak KA. Multidimensional assessment of pain in pediatric sickle cell disease. J Pediatr Psychol 2001; 26(4): 203-14.

48.Hildenbrand AK, Nicholls EG, Daly BP, Marsac ML, Tarazi R, Deepti R. Psychosocial and pharmacological management of pain in pediatric sickle cell disease. Postgrad Med 2014; 126(2): 123-33.

49.Hankins JS, Aygun B, Nottage K, et al. From infancy to adolescence: fifteen years of continuous treatment with hydroxyurea in sickle cell anemia. Medicine (Baltimore) 2014; 93(28): e215.

50.Akingbola TS, Tayo BO, Salako B, et al. Comparison of patients from Nigeria and the USA highlights modifiable risk factors for sickle cell anemia complications. Hemoglobin 2014; 38(4): 236-43.

51.Akinsulie AO, Temiye EO, Akanmu AS, Lesi FE, Whyte CO. Clinical evaluation of extract of Cajanus cajan (Ciklavit) in sickle cell anaemia. J Trop Pediatr 2005; 51(4): 200-5. 